\title{
Contrastes en torno a la construcción del pasado indígena regional en espacios museográficos del sudeste bonaerense: un acercamiento desde las historias institucionales ${ }^{1}$
}

\section{Contrasts around the construction of the regional indigenous past in museums of Southeast Buenos Aires: an approach from institutional history}

\author{
Felicitas Sánchez Azcárate \\ Laboratorio de Arqueología Regional Bonaerense, \\ Universidad Nacional de Mar del Plata, Argentina \\ feli21_sanchez@hotmail.com
}

\begin{abstract}
Resumen
En este trabajo se analizan los modos en que se representa el pasado indígena regional en dos espacios museográficos del sudeste de la provincia de Buenos Aires: el Museo Histórico "Fuerte Independencia" (Tandil) y el Museo Municipal "José Hernández" (Mar del Plata). Se considera que estas instituciones, al constituirse en ámbitos de educación no formal, son susceptibles de indagar las particularidades de sus procesos históricos fundacionales, desarrollos institucionales posteriores e identificar aquellos factores que posibilitaron la generación de perspectivas expositivas y discursivas contrastantes sobre el pasado local y regional. Se evalúa la incidencia del carácter público y privado de esos museos y el rol que adquirió la "Museografía Tradicional" y las "Asociaciones Tradicionalista" en la producción de discursos estereotipados sobre las sociedades indígenas pampeanas.
\end{abstract}

Palabras clave

Pasado indígena; Museos regionales; Educación no formal; Museografía Tradicional; Asociaciones Tradicionalistas

\footnotetext{
1 Este trabajo es el resultado de una beca de Estimulo a las Vocaciones Científicas otorgada por el Consejo Interuniversitario Nacional (CIN) en el año 2014.

Esta obra está sujeta a la Licencia Reconocimiento-NoComercial-CompartirIgual 4.0 Internacional de Creative Commons. http://creativecommons.org/licenses/by-nc-sa/4.0/ (cc) BY-NC-sa
} 


\title{
Felicitas Sánchez Azcárate
}

\begin{abstract}
This research work analyses the ways in which the regional indigenous past is displayed in two museums of the Buenos Aires Province: History Museum "Fuerte Independencia" (Tandil) and Municipal Museum "José Hernández" (Mar del Plata). For being developed based on non-formal educational environments, it is considered that these two institutions are capable of looking into the particulars of their foundational historic processes and subsequent institutional developments, and identifying those factors enabling to create contrasting exhibition and display methods on the local and regional past history. The influence of the public and private character of these museums is evaluated, along with the role "Traditional Museography" and "Traditionalist Associations" played on the production of new stereotyped discourses about indigenous communities in the "Pampas."
\end{abstract}

\section{Keywords}

Indigenous Past; Regional Museums; Non-Formal Education; Traditional Museography; Traditionalist Associations

\section{Introducción}

Desde hace poco más de 30 años los museos comenzaron a ser objeto de investigación para los cientistas sociales. En Argentina fue la disciplina arqueológica la pionera sobre estos estudios ${ }^{2}$. Desde la historia el interés por dichos espacios surgió recién a partir del último cambio de siglo y se relacionó con el análisis de los diversos actores que configuran la memoria histórica de la sociedad, así como los recursos y mecanismos empleados al respecto ${ }^{3}$. En este marco, las instituciones museológicas son concebidas como ámbitos de educación no formal -en términos de su actividad de transmisión cultural- que intervienen activamente en la configuración de representaciones sociales sobre el pasado 4 . Los museos históricos, surgidos junto a la consolidación del Estado, fueron considerados como dispositivos asociados a la construcción de identidades

\footnotetext{
2 Entre ellos se destacan los trabajos de Isabel Lamonier. Museo y Sociedad, Centro Editor de América Latina, Buenos Aires.1993; Marta Dujovne. Entre musas y musarañas. Una visita al museo. Fondo de cultura económico, Montevideo.1995; José Antonio Pérez Gollán. "La situación del patrimonio cultural en la Argentina, Mesa redonda: en el país de nomeacuerdo, Ciencia Hoy 3 (16): 32.1991.

${ }^{3}$ María Elida Blasco. Un museo para la colonia. El Museo Histórico y Colonial de Luján (1918-1930), Rosario: Prohistoria, pp. 21-139. 2011; Irene Brichetti. La construcción del pasado regional en museos del sudeste de la provincia de Buenos Aire. Tesis de Licenciatura en Historia, Facultad de Humanidades de la Universidad Nacional de Mar del Plata, 2008; Mariano Nagy. "Los museos de la última frontera bonaerense y sus narrativas acerca de los pueblos indígenas". Revista del Museo de Antropología. Facultad de Filosofía y Letras 6: 79-90. UBA. ISSN: 1852-060X, 2013.

${ }^{4}$ Como bien afirma María Eugenia Conforti, la educación no formal incluye todas aquellas propuestas educativas estructuradas en contextos que no están diseñados específicamente para las relaciones de enseñanza-aprendizaje; no sólo el museo sino otras, como por ejemplo la ciudad, las casas de cultura, sociedades de fomento, clubes, etc. María Eugenia Conforti. "Educación no formal y patrimonio arqueológico. Su articulación y conceptualización”. Intersecciones en Antropología. Facultad de Ciencias Sociales - UNCPBA - 11: 103-114. 2010. ISSN 1666-2105, 2010, p 6.
} 


\section{Contrastes en torno a la construcción del pasado indígena regional en espacios museográficos del sudeste bonaerense: un acercamiento desde las historias institucionales}

nacionales. Se evidenciaba que durante el proceso de formación de la nación argentina, a partir de la segunda mitad del siglo XIX, se dispusieron una serie de instituciones, entre las que se destacó la educación formal en las escuelas y no formal en establecimientos como los grandes museos de ciencias, cuya principal función era forjar una identidad común, única y homogénea que sentará las bases del país en formación 5 .

Como resultado del proceso antes descripto, los actores sociales que no se adecuaban a la imagen que se suponía que debía encarnar el ser nacional fueron excluidos o relegados del relato histórico dominante y, como consecuencia, de las instituciones educativas que lo reflejaban y difundían. De esta forma, amplios colectivos sociales como los pueblos indígenas o los afrodescendientes fueron invisibilizados. Específicamente, los pueblos nativos fueron subsumidos a un rol pasivo en la historia de la formación de esa identidad y ubicados en la prehistoria como parte de un pasado natural y primitivo.

Si bien desde hace algunas décadas esta perspectiva ha cambiado y las sociedades indígenas son incorporadas en los relatos históricos, esto no parece tener correlato en ciertos espacios museográficos. Esta problemática guarda relación directa con el devenir histórico de cada institución: mientras algunos museos han actualizado su concepción museológica, renovando su discurso sobre el pasado mediante vínculos entablados con especialistas, universidades nacionales y/o centros de estudios especializados, otros en cambio, han continuado alejados de los ámbitos científicos, reproduciendo una concepción decimonónica sobre estos espacios, el patrimonio e incluso la memoria histórica.

Por esta razón, entre las temáticas abordadas por historiadores y antropólogos que analizan los museos y sus problemáticas se destaca la búsqueda por develar las narrativas hegemónicas y las representaciones sociales que construyen y/o reproducen los espacios museográficos sobre el pasado ${ }^{6}$.

El siguiente artículo se enmarca dentro de esta línea investigativa ya que busca indagar las historias institucionales y el origen de las colecciones arqueológicas de dos museos históricos ${ }^{7}$ emplazados en el sudeste de la provincia de Buenos Aires: el museo histórico "Fuerte Independencia" ubicado en Tandil, ciudad cabecera de partido homónimo y, en segundo lugar, el museo municipal "José Hernández", situado en la Reserva integral Laguna de los Padres a unos $25 \mathrm{~km}$ de la ciudad de Mar del Plata, partido de General Pueyrredón. El primero de ellos corresponde a la

\footnotetext{
${ }^{5}$ María Luz Endere y José Luis Prato. Patrimonio, ciencia y comunidad. Su abordaje en los partidos de Azul, Olavarria y Tandil. INCUAPA, UNCPBA, 2009, pp. 19-37.

${ }^{6}$ María Elida Blasco. Un museo para la colonia..., Op. Cit., pp. 121-139; Nagy Mariano. "Los museos de la última..."Op. Cit. pp. 79-90.

${ }^{7}$ Adoptamos la definición de Museo elaborada por el Consejo Internacional de Museos (ICOM) que lo define como: "una institución permanente, sin fines de lucro, abierta al público, al servicio de la sociedad y su desarrollo, que adquiere, conserva, investiga, comunica y exhibe, con fines educativos y de promoción social, testimonios materiales del hombre y su entorno".
} 


\section{Felicitas Sánchez Azcárate}

órbita privada, mientras que el segundo desde el año 1996 fue traspasado al ámbito municipal.

Ambas instituciones museológicas poseen características en común, como el hecho de haber sido fundadas en la década de 1960 bajo el amparo de asociaciones tradicionalistas. A su vez, están ubicadas en ciudades del sudeste bonaerense Tandil y Mar del Plata- que reciben una gran afluencia turística durante la mayor parte del año. Por último, en ambos sitios existen centros de estudios históricos y universidades nacionales en donde se desarrollan conocimientos actualizados sobre la historia regional.

Sin embargo, las instituciones propuestas reconstruyen y difunden versiones diferentes sobre el pasado milenario regional: mientras que el museo de Tandil se limita a representar la cuestión indígena mediante una serie de objetos y/o materiales alusivos a estas sociedades -dispuestos en forma aleatoria sin referencias precisas ni ningún criterio temporal ni espacial que posibilite el acercamiento a la forma de vida de éstas sociedades-, el museo de Mar del Plata presenta un enfoque distinto que contempla a las poblaciones indígenas a partir de una muestra contextualizada, dinámica e interactiva que posibilita un acercamiento al pasado regional contemplado la diversidad de actores que lo configuran.

A partir del análisis de documentación inédita conservada en los archivos institucionales de ambos espacios museográficos, entre los que se destacan Estatutos y Cuadernillos Informativos, y de entrevistas semiestructuradas efectuadas a sus directivos se pretende develar de qué forma las historias de ambos museos influyen y/o condicionan la mirada actual que transmite cada uno en torno al pasado milenario regional. Asimismo y de modo complementario, se analizarán artículos periodísticos de alcance local y nacional, y bibliografía édita sobre la temática en cuestión con el fin de contextualizar el periodo analizado. Por último, se dispone del Informe de Asesoramiento Museológico para el Museo Municipal "José Hernández", elaborado entre los años 1996-1997, que cuenta con valiosa información para abordar el devenir histórico de esta institución.

\section{Historia del Museo Histórico "Fuerte Independencia"}

El 20 de agosto de 1955 se crea en la ciudad de Tandil la Institución tradicionalista "Fuerte Independencia". ${ }^{8}$ Su fundación se originó por iniciativa de vecinos de la ciudad, amantes del folklore y de las tradiciones criollas. La comisión encargada de llevar adelante este proyecto estaba precedida por Carlos de Ferrari Bravo, junto a una comisión integrada por catorce personas ${ }^{9}$. En palabras de sus fundadores el nombre Fuerte Independencia había sido elegido“...en homenaje a aquella

\footnotetext{
8 Estatuto de la Asociación, 1964. p. 1.

${ }^{9}$ Entre éstos se destacaban: Cecilia S. de Freceise Rico, Sante Salvador, Emilse Gianibelli, Rodolfo Saling, Julio C. Escobar, Teresa C. de Saling, Leonel Acevedo Díaz, Alfredo Serres, Emilio Ramos, Leonetto Binelli, etc.
} 


\section{Contrastes en torno a la construcción del pasado indígena regional en espacios museográficos del sudeste bonaerense: un acercamiento desde las historias institucionales}

avanzada heroica en la lucha de fronteras que así llamará su jefe, y a la vez fundador de nuestra ciudad, el Brigadier General Don Martin Rodríguez"10. Dicha avanzada sobre los indígenas determinará la ideología imperante desde la fundación del museo en torno a la representación sobre los pueblos nativos.

Durante los primeros años la institución se centró en la enseñanza de las danzas criollas, con el principal objetivo de defender el patrimonio folklórico nacional. En esta etapa, algunos integrantes de la comisión directiva realizaron distintos viajes a la República Oriental del Uruguay entre los años 1957, 1958, 1960 y 1961, invitados por la Institución Tradicionalistas uruguaya "El Pericón". En 1958 durante uno de estos viajes, participaron del Primer Congreso Tradicionalista del Río de la Plata, el cual se realizó en el Ateneo de la ciudad de Montevideo y concurrieron delegaciones de países como Argentina, Uruguay y Brasil. El objetivo central era establecer pautas comunes para orientar y estructurar al conjunto de instituciones tradicionalistas de la región ${ }^{11}$.

De esta forma comenzaban a estrechar vínculos con otras entidades de similares características. Por otro lado, la enseñanza de las danzas nativas para niños y adultos, la realización de fogones periódicos, conferencias, festivales musicales y de poesías criollas, exhibiciones de destreza gaucha y exposiciones de artes plásticas ${ }^{12}$, fueron otorgándole cada vez mayor visibilidad dentro del ámbito cultural y social de la ciudad.

El 8 de junio de 1960 surgirá desde el seno de la comisión directiva una subcomisión compuesta por Emilse Giannibelli, Carlos Alllende y Domingo Polpadre que impulsará la creación de una biblioteca folklórica tradicionalista. En este marco, surgió la necesidad de adquirir un espacio propio para instalar la biblioteca y desarrollar el resto de las actividades, hecho que se concretó en el año 1962.

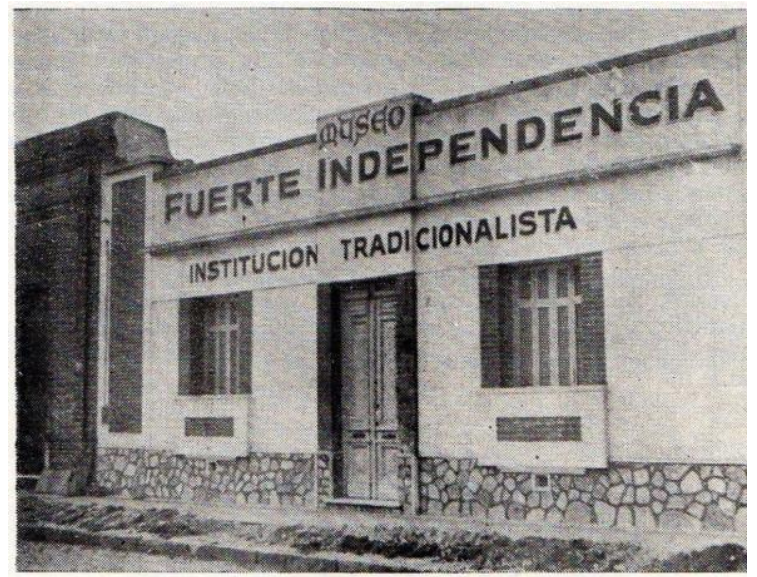

Figura 1: Fachada original del Museo Tradicionalista Fuerte Independencia. Calle 4 de abril 845. Año 1963. Archivo de la Institución.

\footnotetext{
${ }^{10}$ Cuadernillo informativo de la Inauguración y actividades del Museo y Biblioteca "Fuerte Independencia", Septiembre de 1963, p. 1.

11 Ibídem.

${ }^{12}$ Cabe destacar que el artista plástico tandilense Carlos Allende era integrante activo de la comisión directiva.
} 


\section{Felicitas Sánchez Azcárate}

Ya instalados en la calle 4 de abril al 845, bajo la dirección del artista Carlos Allende, surgirá la idea de fundar un Museo. De esta forma, el 7 de septiembre de 1963 se inaugurará el Museo Tradicionalista "Fuerte Independencia". Apadrinado por figuras destacadas de la ciudad como Antonio Santamarina y Rosa G. A. de Lalloz, y bendecido por el Monseñor Luis J. Actis, se creaba el primer y único museo que trasmitía y divulgaba el pasado histórico de la ciudad (Figura 1). Presidía entonces la institución Ricardo Ballent, junto a una comisión directiva de catorce miembros.

El surgimiento y desarrollo del museo, por aquel entonces denominado "Museo Tradicionalista Fuerte Independencia"13, se debió a las donaciones realizadas por vecinos de la ciudad y a la entrega en "custodia"14 de otros tantos objetos, generando que a solo un año de iniciadas las tareas la institución contara con más de 600 piezas de "valor histórico"15. Esto último estuvo íntimamente ligado al fenómeno del coleccionismo y el museo tuvo su origen en el traspaso de las colecciones del ámbito estrictamente privado al público.

\section{El museo y sus colecciones}

Durante los primeros años la institución estuvo conformada solo por cuatro salas en las que se exhibían diversos objetos como la bandera Argentina correspondiente al Batallón 1ero de Guardias Nacionales, marcas de hacienda, frenos y roldanas de jagüeles, armas utilizadas por el ejército durante la "Campaña del Desierto", piezas de carretas, cañones pertenecientes a lo que había sido el Fuerte Independencia, entre otros. También existía en una de las salas la reconstrucción de una pequeña Pulpería que incluía distintas piezas propias del periodo colonial. En otra sala se representaba la historia del alambrado, aunque también se exponían objetos de la vida cotidiana como faroles a kerosene y ollas. Cabe destacar la presencia de un carruaje del año 1827 perteneciente a Rómulo Pereyra Iraola, donado a la institución por Antonio Santamarina, reconocido coleccionista y ex intendente de la ciudad.

En la actualidad el museo cuenta con un total de dieciséis salas conformadas por numerosos objetos. Los aficionados locales desempeñaron un rol central en la conformación del fondo museográfico, donando desde colecciones arqueológicas, faunísticas y numismáticas hasta objetos con valor histórico como documentos,

\footnotetext{
${ }^{13}$ El museo sufrió un cambio en su denominación. En los inicios y por el tipo de proyecto que pretendían conformar se llamaba "Museo Tradicionalista Fuerte Independencia". Pero debido a la gran cantidad de documentos históricos que había ido adquiriendo la institución, las personas a cargo de la Biblioteca/Archivo decidieron que era más apropiado denominarlo "Museo Histórico Fuerte Independencia". Fue así que a comienzos de la década de 1990 el Museo cambió de nombre. ${ }^{14}$ Por aquel momento los vecinos entregaban en custodia determinadas piezas consideradas con valor histórico. Con el paso del tiempo, la mayoría de esas piezas pasaron a formar parte del acervo cultural del museo. Pero podía suceder que el dueño de la pieza la reclamara y la institución debía devolverla.

${ }^{15}$ Cuadernillo informativo de la Inauguración y actividades del Museo y Biblioteca "Fuerte Independencia", Septiembre de 1963, p. 2.
} 


\section{Contrastes en torno a la construcción del pasado indígena regional en espacios museográficos del sudeste bonaerense: un acercamiento desde las historias institucionales}

fotografías, instrumentos musicales, prendas, armas, vehículos de época, aviones, pinturas, etc.

Salvo algunas excepciones, existe poca información sobre el origen de los objetos que conforman el fondo museográfico de la institución, nunca se realizó un seguimiento sistemático de qué ingresaba, quién lo donaba o dejaba "bajo custodia", cuándo se efectuaba la entrega, etc. Mediante una entrevista realizada a un integrante de la comisión directiva, se pudo comprobar que salvo una colección de puntas de proyectil líticas que la institución compró durante sus primeros años de existencia, todo el patrimonio ha sido adquirido a través de donaciones o de la "entrega en custodia".

Partiendo de los datos recopilados se puede afirmar que fueron pocos los donantes que entregaron grandes colecciones, entre ellos sobresalen las familias Santamarina, Allende, Figueroa y Olivero. Las colecciones donadas por dichas familias, pertenecientes a un sector social destacado de la ciudad, estuvieron integradas en su mayoría por objetos antiguos o "de época" y objetos gauchescos: carruajes, pinturas, mates, herraduras, estribos, cuchillo, etc. Solo se distingue el caso de Eduardo Olivero -aviador tandilense que participó en la Primera Guerra Mundial- quién donó una serie de objetos relativos a su experiencia como aviador: fotos, placas, banderas de guerra y libros, que conforman actualmente la primera sala del museo.

No puede dejar de mencionarse el rol central que desempañaron las Fuerzas Armadas en la conformación del museo. Uniformes, medallas, cañones, tanques, aviones y minas constituyen una parte importante del acervo cultural y llegaron a la institución a través de donaciones realizadas por militares. Pudo comprobarse a través de entrevistar a allegados a Ricardo Ballent, que éste actuó como "puente" entre ambas instituciones. Ballent, que junto con Carlos Allende fueron los fundadores del Museo y presidió la institución hasta su muerte en el año 2005, se interesaba mucho por mantener lazos con las Fuerzas Armadas, nunca faltaba a los actos militares, festejaba las fechas patrias e invitaba a generales y tenientes al museo para rendirles homenaje. Su labor profesional como martillero público y su identidad patriótica -entendida ésta en términos políticos/militares- posibilitaron la creación de vínculos con familias tradicionales de la ciudad, así como con las Fuerzas Amadas.

\section{Ampliaciones}

A medida que el museo fue creciendo la comisión directiva comenzó a plantearse la necesidad de realizar refacciones, ampliaciones y la posibilidad de comprar inmuebles linderos. Si bien no se cuenta con información precisa acerca de las distintas etapas ni de la compra de los terrenos aledaños, se estima gracias a las entrevistas efectuadas que la última ampliación se efectúo hace 20 años (Figura 2). 


\section{Felicitas Sánchez Azcárate}

Luego de comprar el inmueble original, se adquirió el galpón que actualmente alberga la sala "Don Carlos Ballent" y la sala "Imágenes Religiosas". Posteriormente se anexó la totalidad del terreno, que continua hasta la calle 4 de abril. En un segundo momento se adquirió el galpón que alberga la Sala "El Campo" y un inmueble situado sobre la Avenida Marconi ubicado en la misma manzana que el Museo, donde se encuentran hoy las salas 10, 11, 12 y 13.

Las salas 12 y 13 ("Telégrafo/Ferrocarril y "Ciencias Naturales") fueron construidas a partir del cierre de dos museos que existían en la ciudad: el "Museo Ferroviario"16 que estaba ubicado en las calles Aristóbulo del Valle y Alem, fundado en 1994 y, el "Museo de Ciencias Naturales" que desde el 2005 funcionaba en la calle Mitre al 38617. Ambos debieron concluir sus actividades por cuestiones económicas y se trasladaron al Museo Histórico entre los años 2011 y 2013. La última ampliación que se realizó fue la compra del galpón donde se encuentra la sala 16 "Don Carlos Allende".

En el año 2000 se inauguró la sala de los carruajes (hoy "El Campo") y se recibió la donación de las pertenencias del escultor Carlos Allende. Durante el 2010 comenzó a remodelarse la sala "La Farmacia" que se inauguró en julio del 2011 gracias a la donación de la familia Berlari, quienes cuatro años antes habían cedido todo el mobiliario: frascos, balanzas, botiquines y demás elementos de la histórica Farmacia Central, ubicada en Rodríguez al 400. La obra se financió con los recursos reunidos en un asado que el Museo realizó por los festejos del Bicentenario en las instalaciones de la Sociedad Rural. ${ }^{18}$

Pero el evento que hasta la actualidad constituyó la mayor atracción para los miembros de la comisión directiva fue la inauguración de la Sala "Islas Malvinas", que finalmente se concretó en mayo del 2014 luego de 3 años de trabajo y complicaciones financieras ${ }^{19}$. La fecha elegida fue el 1 de mayo en conmemoración al bautismo de fuego de la fuerza aérea en la Guerra de Malvinas. Para los miembros de la comisión esta sala es la más moderna e interactiva ${ }^{20}$.

\footnotetext{
${ }^{16}$ La Nación, Buenos Aires, 9/07/2005.

17 Ordenanza Municipal № 8060/2000. Creación del “Museo de Ciencias Naturales”, Tandil, 2005.

18 El Eco de Tandil, Tandil, 9/08/2011, p. 25

${ }^{19}$ La Voz de Tandil, Tandil, 16 /12/2011, p. 23

${ }^{20}$ El Eco de Tandil, Tandil, 2/05/2014; El Diario de Tandil, Tandil, 30/04/2014.
} 
Contrastes en torno a la construcción del pasado indígena regional en espacios museográficos del sudeste bonaerense: un acercamiento desde las historias institucionales

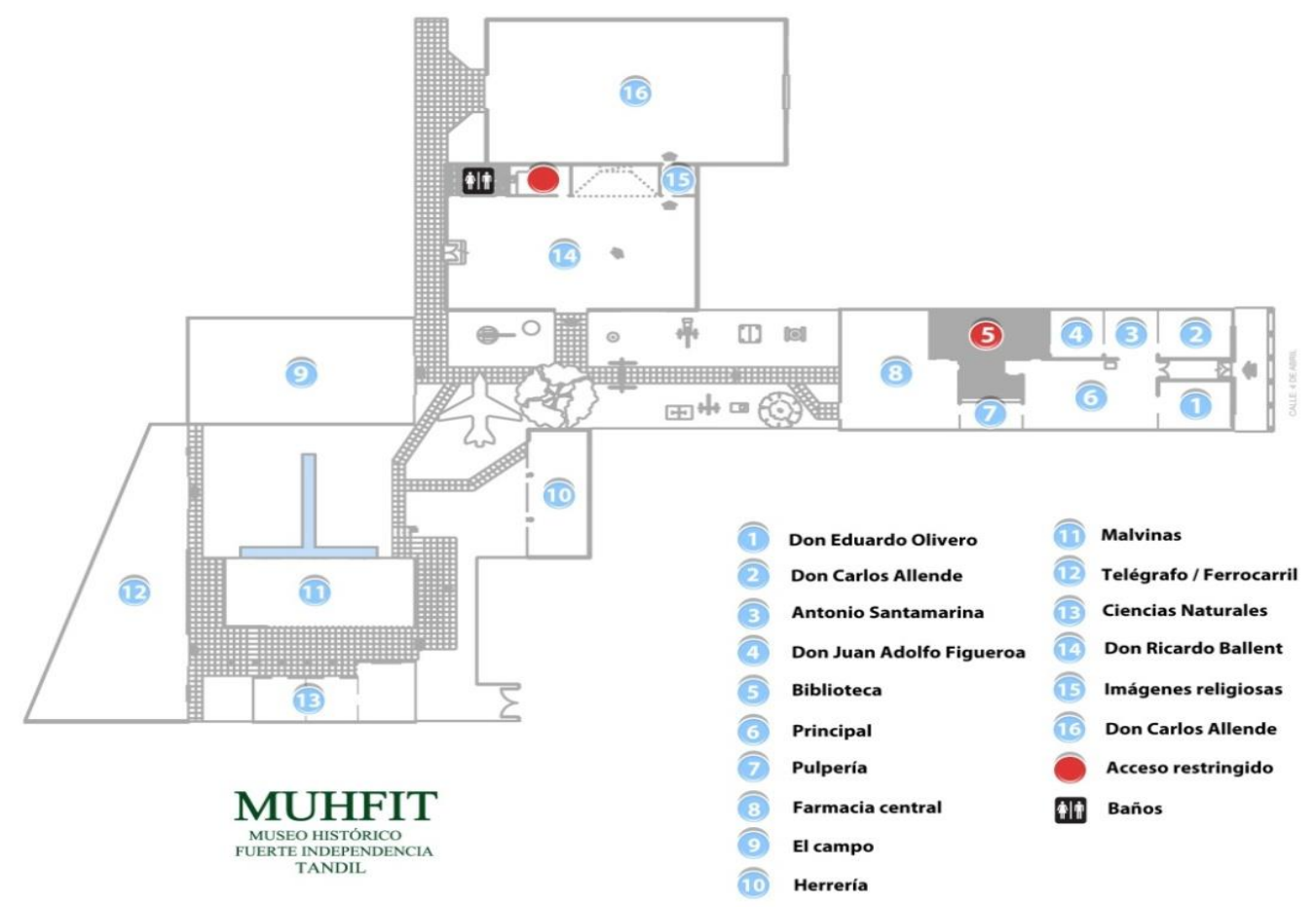

Figura 2: Plano actual del Museo Histórico Fuerte Independencia. Archivo de la institución.

\section{La cuestión indígena en la muestra}

Las poblaciones indígenas de la región aparecen representadas en la Sala 2 del museo, denominada "Don Carlos Allende". Este espacio está compuesto por restos materiales -puntas de proyectiles, morteros, vasijas, lanzas e imágenes- ubicados de forma azarosa e intercalados con objetos gauchescos. Las vitrinas no exponen información sobre los modos de vida indígena, es un tema relegado en la muestra del museo. Este aspecto tiene vinculación directa con la tendencia tradicionalista y militarista que predomina en las salas, en donde el gaucho es el sujeto social que adquiere mayor jerarquía y visibilidad a la hora de abordar el pasado regional.

En este caso, la cuestión indígena aparece aislada, simplificada y detenida en el tiempo, generando la imposibilidad de representar a estos pueblos en interacción con la "sociedad blanca".

\section{Historia del Museo Municipal “José Hernández”}

El Museo Municipal "José Hernández" se encuentra ubicado en los predios de la Reserva Integral Laguna de los Padres a $25 \mathrm{~km}$ de la ciudad de Mar del Plata, en el área rural del Partido de General Pueyrredón. El edifico donde está instalado el museo perteneció al casco de la antigua Estancia Laguna de los Padres, construido 
entre 1885 y 1886, por su propietario Eusebio Zubiaurre (Figura 3). Por aquel entonces era una extensa propiedad ganadera ${ }^{21}$.

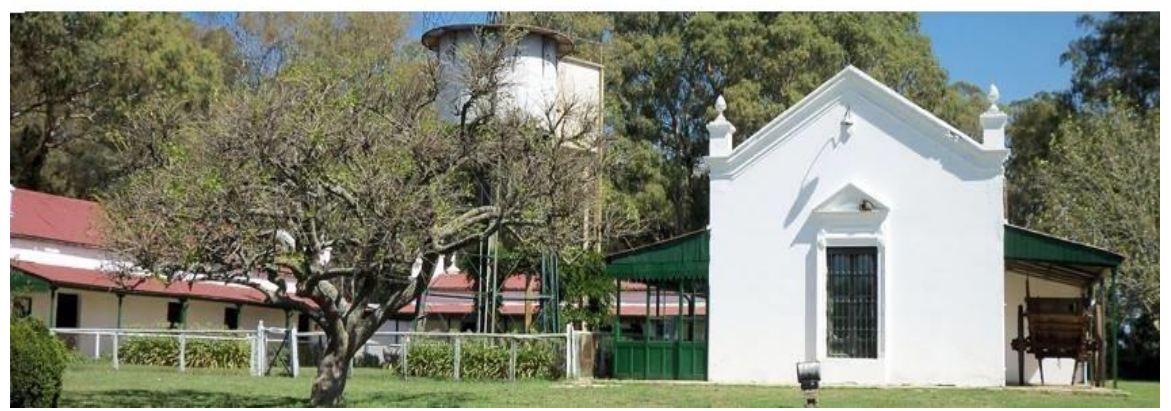

Figura 3: Casco histórico donde está emplazado el Museo Municipal José Hernández. Foto actual. Archivo de la Institución

El museo fue creado en el año 1960, pero la historia de la institución comenzó a fines de la década de $1940^{22}$. Durante aquel periodo el gobierno de Juan Domingo Perón impulsó una política agraria que dio lugar a un proceso de expropiación de un conjunto de predios rurales cercanos a los ejidos urbanos, entre los cuales se encontraba la "Estancia Laguna de los Padres", cuyo casco años después se transformará en el edificio que alberga al museo. El gobernador Domingo Mercante (1946-1952) fue quien propulsó dicha política en la provincia de Buenos Aires que tuvo como objetivo la formación de colonias rurales y la delimitación de reservas ecológicas a modo de parques. Sin embargo, estas medidas tuvieron un carácter simbólico, ya que el proceso de expropiación no estuvo articulado a ningún plan agrario nacional.

En este contexto y hacia fines de la década de 1950 un grupo de vecinos de la ciudad de Mar del Plata ${ }^{23}$ propició la idea de crear una institución cuya finalidad fuera mantener y difundir las "tradiciones nacionales" en sus diferentes manifestaciones. Consideraban que para transmitir la cultura tradicionalista en forma permanente era necesario crear un museo y propusieron que se emplazara en la Laguna de los Padres, dado que ésta “...fue asiento de la primera avanzada de la civilización en esta parte del sudeste bonaerense representada por la Reducción del Pilar (hoy reconstruida); centro, por decirlo así, de los establecimientos ganaderos de aquel entonces; por haber sido allí donde José Hernández paso su juventud, se hizo diestro de los trabajos del campo, y dominó el ganado, penetró en lo íntimo del gaucho cosechando sabidurías y experiencias que luego volcó en su

${ }^{21}$ Informe de Asesoramiento Museológico para el Museo Municipal José Hernández (1996-1997), p. 6.

${ }^{22}$ La historia de la Estancia "Laguna de los Padres" se remonta a las primeras décadas del siglo XIX, este trabajo se limitará a abordar la historia de Museo que allí se emplaza. Para conocer sobre la historia de la estancia ver Cesar Román. Cuando Mar del Plata era Campo. Ediciones Suarez, 2004.

${ }^{23}$ Entre los que se destacaban Esteban H. Aguirre, Alfredo D. Rabellino, Ernesto Cilley Hernández, Tomas Vignolo, Ignacio Leal Lasota, Gregorio Gorozo, José Argentino Zoppi, Miguel Borthiry, Roberto Damián Núñez, Dardo Moya y Héctor Vezzi Sendra. 


\section{Contrastes en torno a la construcción del pasado indígena regional en espacios museográficos del sudeste bonaerense: un acercamiento desde las historias institucionales}

poema "Martin Fierro"24. De este modo, entendían que dicho sitio era representativo de la "argentinidad" ya que materializaba la avanzada sobre ese territorio y sobre las poblaciones que lo habitaban.

Esta inquietud fue transmitida a los círculos gubernamentales y coincidió con la organización de los festejos del Sesquicentenario de la Revolución de Mayo. En este contexto, la creación del museo era un hecho político en sincronía con las celebraciones programadas.

Para concretar la formación del museo se creó la Comisión Pro Museo Tradicionalista Argentino José Hernández que será el ente encargado en llevar adelante la administración durante sus primeros años ${ }^{25}$. De esta forma, 11 de marzo de 1960 se inauguraba el "Museo Tradicionalista Argentino José Hernández". El nombre elegido se debía a la creencia generalizada de que el autor del "Martin Fierro" había vivido en el Casco de la Estancia durante su adolescencia ${ }^{26}$. El acto inaugural incluía un programa en donde participaban reconocidas personalidades políticas y religiosas tanto del ámbito local como nacional 27 .

Cuando el museo se aproximaba a cumplir un año comenzaron las tratativas para adquirir la personería jurídica, hecho que se concretó el 11 de diciembre de 1963. En este contexto, se resuelve constituir la "Asociación Museo Tradicionalista Argentino José Hernández", la cual continuaría la labor llevada adelante hasta el momento por la "Comisión Pro Museo Tradicionalista Argentino José Hernández". Se conformaron así las diferentes comisiones que integrarían la asociación: Comisión Directiva, Revisora de Cuentas, Asesora y de Prensa, y Propaganda. Alfredo D. Rabelli y Delia V. de Rabellino fueron los encargados de firmar el acta de asamblea ${ }^{28}$. Esta estructura administrativa se mantendría intacta hasta el año 1996.

\section{El museo y sus colecciones}

Los primeros vínculos institucionales para constituir las exposiciones del museo se establecieron con el señor Horacio González Solar, representante del Museo

\footnotetext{
${ }^{24}$ Cuadernillo informativo de circulación interna de la Asociación Museo Tradicionalista Argentino José Hernández (1963-1975), p.1.

25 La Nación, Buenos Aires, 26/02/1960.

26 Sin embargo, recientemente se constató que dicho personaje estuvo por esta zona durante la década de 1840, mientras que la construcción del casco de la Estancia se remite a mediados de la década de 1880, razón por la cual no es posible que Hernández haya pasado su adolescencia allí. Sobre este tema ver: Felicitas Sánchez Azcárate. "Cuando el mito supera la realidad: La figura de José Hernández y su pasaje por la Laguna de los Padres”, presentado en II Jornadas Martinfierristas, Ayacucho, Buenos Aires, 2013.

27 La Capital, Mar del Plata, 11/03/1960, p.25

${ }^{28}$ Cuadernillo informativo de circulación interna de la Asociación Museo Tradicionalista Argentino José Hernández (1960-1975), p. 12.
} 


\section{Felicitas Sánchez Azcárate}

“Motivos Populares Argentinos José Hernández" de la ciudad de Buenos Aires. Dicha institución aportó piezas, vitrinas y personal encargado de su custodia.

Por otro lado, se le propuso al intendente municipal de entonces, Teodoro Bronzini, que ceda el busto del General Juan Martin de Pueyrredón que se hallaba en el corralón municipal. El mandatario aceptó y el busto fue emplazado en la entrada del casco histórico, siendo parte del programa propuesto para el día de la inauguración del museo. También se adquirió por parte de la dirección de la Escuela № 13 del Partido de General Pueyrredón, el busto de José Hernández que ocupó un lugar destacado en las salas ${ }^{29}$.

En el mes de octubre de 1960 José Argentino Gianelli donó una importante colección y, además, aceptó ocuparse de la atención del Museo. En noviembre se lo designó formalmente encargado del museo ${ }^{30}$.

En adelante el ingreso de piezas y/u objetos con valor histórico se incrementó gradualmente, generando que el patrimonio del museo comenzara a enriquecerse. En el año 1965 se inauguró una sección dedicada exclusivamente a Mar del Plata con piezas de Lorenzo Scaglia ${ }^{31}$, autodidacta de reconocida trayectoria nacional, y de la Municipalidad de General Pueyrredón.

Al cabo de algunos años y gracias a la adquisición de colecciones más numerosas conformadas por objetos gauchescos, arqueológicos, armas de fuego, uniformes militares, piezas numismáticas y carruajes, la institución terminó de configurar su perfil tradicionalista.

La muestra museográfica -conformada por siete salas- estaba centrada en la figura del gaucho, considerado el emblema de la argentinidad. En las muestras se exponían objetos que representaban temáticas tales como: "El Gaucho figura ecuestre”, “El Fortín”, “Misiones Jesuitas y Primeros Pobladores”, “José Hernández: el Martin Fierro", "La estancia Laguna de los Padres" y "La Fundación de Mar del Plata". Por su parte, las sociedades indígenas aparecían representadas en la Sala 4, junto con las Misiones Jesuitas. Integraban este espacio fotografías, dibujos y textos sobre el asentamiento jesuita instalado en la Reducción Nuestra Señora del Pilar, a poca distancia del actual museo. Por último, conformaban la sala una colección de instrumentos líticos entre los que se encontraban lascas, percutores, puntas y núcleos. ${ }^{32}$

La colección de material lítico era lo único que el museo exhibía relacionado a las sociedades indígenas, lo que permite afirmar que estos pueblos eran representados solo a partir de dichos instrumentos. En este sentido, se reproducía una visión simplista, ahistórica y estereotipada del indígena.

\footnotetext{
29 Ídem, p. 5.

30 Ídem, p. 7.

31 Para mayor información sobre este personaje y su trayectoria como coleccionista ver: Irene Brichetti. "Sabios, exploradores y artesanos. Amalgamas del pasado en la Mar del Plata de primera mitad del siglo XX (1924-1954)”. RMA Museología, 2014.

32 Informe de Asesoramiento Museológico para el Museo Municipal José Hernández (1996-1997), pp. 17-19.
} 


\section{Contrastes en torno a la construcción del pasado indígena regional en espacios museográficos del sudeste bonaerense: un acercamiento desde las historias institucionales}

\section{Un cambio de rumbo}

Durante 36 años la Asociación Tradicionalista fue la encargada del funcionamiento del museo y bajo su responsabilidad se encontraban el edificio y los terrenos circundantes. El rol de la institución durante esta etapa se relacionó con la exhibición de objetos gauchescos, la realización de jineteadas anuales y otras actividades de difusión.

En el año 1996 el museo es traspasado al ente de Cultura de la Municipalidad de General Pueyrredón, quedando bajo la dependencia de su Secretaría de Cultura. Desde el municipio aludían que el casco histórico no se estaba preservando adecuadamente y que el museo se mantenía abierto pocos meses al año, ambas cuestiones íntimamente relacionadas.

Durante los primeros años que transcurrieron luego del cambio de administración y con el fin de regularizar el accionar de la institución, se constituyó una comisión de enlace que perduró hasta 1998. Dicha comisión, además de incorporar a la Licenciada en antropología Ana Lía Verón, buscaba incluir a los miembros de la Asociación Tradicionalista. Sin embargo, con el paso del tiempo esta última iniciativa no prosperaría y la administración del museo recaería sobre la figura de Verón.

A partir del traspaso a la órbita municipal la institución propone renovarse, manifestando la intensión de modificar el discurso museológico ${ }^{33}$. Durante este proceso se cambiará, en parte, la denominación del museo, que pasará de llamarse "Museo tradicionalista Argentino José Hernández" a “Museo Municipal José Hernández".

En este marco se llevará adelante una actividad de cooperación entre dos entidades especializadas: el Grupo de Investigación “Arqueología Regional Bonaerense" (ARBO) dependiente de la Universidad Nacional de Mar del Plata (UNMDP) y el Museo Etnográfico J. B. Ambrosetti, dependiente de la Universidad de Buenos Aires (UBA).

Los objetivos propuestos eran claros: "Realizar un diagnóstico preliminar de las condiciones estructurales del edificio, asesorar respecto de la redefinición del perfil museológico y museográfico, asesorar sobre la elaboración de una política patrimonial y de actividades de difusión e investigación para dicha institución y confeccionar un informe con recomendaciones a corto, mediano y largo plazo ..."34 Se buscaba reconfigurar el perfil de la institución adoptando las funciones esenciales de la museología contemporánea: conservación, difusión, transmisión e investigación. A su vez, se asumía explícitamente que estas instituciones intervienen activamente en la construcción social de representaciones, discursos y narrativas sobre el pasado mediante la interpretación de objetos. La

\footnotetext{
33 Ídem, p. 3.

${ }^{34}$ Informe de Asesoramiento Museológico para el Museo Municipal José Hernández (1996-1997), p. 4.
} 


\section{Felicitas Sánchez Azcárate}

transformación más relevante recaía en el cambio de concepción respecto a la pieza exhibida: el objeto expuesto ya no habla por sí mismo -como suponía la museografía tradicional-, sino que forma parte del complejo sistema de comunicación que la exhibición propone, convirtiéndose en un objeto interpretado. Finalizada la administración de la Licenciada Verón en el año 2001, la dirección del museo se mantuvo acéfala. Recién en el 2008 se creó el cargo de "Jefatura" y se designó a Andrea Basualdo jefa del museo ${ }^{35}$. En ese momento se reconfiguró la estructura orgánica de la institución que pasaría a estar integrada por: un jefe, un superior administrativo, un técnico -encargado de la conservación preventiva de las piezas-, dos personas responsables del servicio educativo y un cajero. La creación de dichos cargos, que se mantienen hasta la actualidad, tuvo como principales objetivos organizar y jerarquizar la institución.

\section{Nuevos vínculos entablados}

El traspaso a la órbita municipal posibilitó la incorporación a un circuito más amplio y dinámico de relaciones que permitió establecer vínculos con otras instituciones. Por un lado, relaciones estrechados con entidades especializadas que colaboran hasta la actualidad con la dinámica diaria del museo, como el caso de la Central Atómica de Ezeiza que brinda ayuda relacionada con la conservación de los documentos que forman parte del patrimonio, el Archivo Histórico de La Plata que ofrece asesoramiento relativo la conservación y análisis de los documentos históricos -cartas, fotografías, etc.-, el museo de Ciencias Naturales de La Plata que colabora con la conservación preventiva de las piezas y/o objetos que conforman el patrimonio del museo, entre otros.

Por otro lado se establecen vínculos interinstitucionales a partir de la conformación de exposiciones itinerantes. En estos casos el museo traslada muestras a otras dependencias ${ }^{36}$ y también recibe muestras temporarias de otras instituciones, entre ellas el museo de ciencias naturales de Corrientes, el museo histórico provincial de Santa Fe y el museo etnográfico J. B. Ambrosetti de la ciudad de Buenos Aires. Por último, la institución ha participado del encuentro anual de museos universitarios en calidad de "museo estatal".

En el año 2004 se concretó un proyecto de extensión universitaria impulsado por el Laboratorio de Arqueología Regional Bonaerense -LARBO/UNMDPdenominado "Los pueblos originarios pampeanos. Identidad, Museología y Arqueología regional", financiado por la Secretaría de Políticas Universitarias ${ }^{37}$. A partir de este, se montó una exposición llamada "Nuestra historia profunda:

\footnotetext{
35 Andrea Basualdo es la jefa actual del MMJH. Es Profesora Nacional de Folklore, título que obtuvo en el año 1997. En el 2013 se recibió de Licenciada en Museología. Gran parte de la información recogida para esta sección se obtuvo a partir de entrevistas dirigidas a ella.

${ }^{36}$ Por ejemplo, se envían muestras a la ciudad de Madariaga para la exposición rural, a Ayacucho para las jornadas "Martinfierristas" o al museo histórico de Balcarce con una exposición relativa al gaucho "Martin Fierro".

37 SPU № 407/04
} 


\section{Contrastes en torno a la construcción del pasado indígena regional en espacios museográficos del sudeste bonaerense: un acercamiento desde las historias institucionales}

arqueología y pueblos originarios" que ocupaba dos salas del área derecha del edificio y estaba integrada por fotografías, información escrita actualizada y contextualizada, periodizaciones, mapas conceptuales, réplicas de vasijas de cerámica indígena, tres dioramas (figuras humanas), secuencias de producción cerámica y lítica, réplicas arqueológicas, y fragmento de fuentes históricas. En este sentido, se logró generar un espacio de divulgación y reflexión sobre la historia milenaria de la región Pampeana y consolidar lazos interinstitucionales con representantes municipales, docentes y la Mesa de Trabajo de los Pueblos originarios Mapuches, entre otros apoyos recibidos.

Los vínculos concretados demuestran que la institución se ha insertado en un circuito de relaciones con entidades especializadas que superan el alcance local/regional. Esto evidencia que el traspaso a la órbita estatal ha sido favorable en este aspecto, ya que las relaciones entabladas dinamizan y sociabilizan aun más el trabajo y las muestras del museo. Al respecto cabe preguntarse de qué manera repercutieron estos cambios y relaciones entabladas en los temas expuestos en el museo. ¿Se transformó el discurso que reproducía y representaba la institución? ¿Qué lugar ocupa la historia indígena desde entonces?

El proceso iniciado en 1996 transformó la concepción del espacio museográfico, entendido desde entonces como un lugar dinámico de educación no formal dónde debe existir la necesaria colaboración de entidades especializadas que posibiliten un acercamiento hacia el pasado contemplando la diversidad sociocultural de actores que lo configuran.

En la actualidad el museo se encuentra conformado por ocho salas. En las primeras cuatro se representa el pasado milenario regional través de dos muestras permanentes tituladas: "Nuestra Historia Profunda" y la "Expansión de la Frontera Ganadera".

En este caso, los pueblos indígenas son interpretados como sujetos activos del pasado regional. La exposición permite aproximarse y conocer la dinámica de los grupos indígenas que allí se encontraban: cómo y de qué vivían, en qué período lo hicieron, qué regiones ocupaban, los vínculos que mantenían con el "hombre blanco", y los procesos y reconfiguraciones que sufrieron a partir de la avanzada del estado nacional sobre su territorio. Por su parte, los objetos no se encuentran expuestos de forma aleatoria, sino que existe un orden claro en el recorrido, lo cual permite que el visitante que desconoce la temática pueda recorrer la muestra sin mayores dificultades.

\section{Consideraciones finales}

El análisis de las historias institucionales y de las colecciones que conforman ambos espacios museográficos permite afirmar que la particularidad de cada proceso fundacional y su posterior desarrollo posibilitaron la generación de diversas perspectivas y representaciones sobre el pasado local, regional e incluso 


\section{Felicitas Sánchez Azcárate}

nacional, así como también distintas maneras de concebir el patrimonio y la memoria histórica.

Como sostiene Puppio ambos espacios museográficos surgieron en un periodo donde la creación de museos en el ámbito de los municipios de la provincia de Buenos Aires, aunque no era un fenómeno nuevo, adquiría características distintivas. Esto se explica a partir de la política estatal en el ámbito de la provincia de Buenos Aires llevada adelante durante los gobiernos peronistas de Domingo Mercante (1946-1951) y Carlos Vicente Aloe (1951-1955), que promovía la creación de museos y una política centralizada en su manejo, ya que se los consideraba instituciones pedagógicas que debían ser planificadas desde el estado $^{38}$. En este contexto que incentivaba la creación de dichos espacios, muchos coleccionistas autodidactas optaron por utilizar distintas estrategias para hacer públicas sus colecciones, hecho que explica en parte la conformación de los dos museos analizados en este trabajo.

A su vez, fueron entidades tradicionalistas las que impulsaron estos espacios en sus comienzos, compartiendo y legitimando a través de la puesta en escena tanto un sistema de creencias como de prácticas profesionales -las de los coleccionistas-. En ambos casos, la historia que reproducían colocaba al gaucho como el actor social que obtenía mayor jerarquía y visibilidad a la hora de abordar el pasado regional. A través de esto se expresaba la objetivación de un discurso cultural/ideológico concreto: el "discurso criollista"39. A partir de las primeras décadas del siglo XX en un contexto caracterizado por la fuerte migración ultramarina, el gaucho adquiría cada vez mayor relevancia y la clase dominante comenzó a exaltar su figura colocándola como emblema de la argentinidad. El gaucho se transformó en objeto de culto capaz de contener los rasgos esenciales de la nacionalidad argentina.40

Pero mientras el museo “José Hernández" renovó su discurso museológico y museográfico a partir del traspaso a la órbita municipal en el año 1996, el museo "Fuerte Independencia" continuó reproduciendo ese "discurso criollista" e incluso militarista. A partir de entonces cabe preguntarse: ¿este relato histórico es representativo de la sociedad tandilense en su conjunto? ¿Qué sucede con los grupos sociales que no se adaptan al modelo imperante que reproduce el museo indígenas, obreros, estudiantes, mujeres, etc.?

La investigación efectuada permite afirmar que la institución estuvo íntimamente relacionada desde sus orígenes al sector dominante de la ciudad de Tandil. Los vínculos entablados con familias destacadas como Santamarina, Allende, Figueroa e incluso Roca, y las Fuerzas Armadas, fueron configurando un perfil ideológico

38 María Alejandra Pupio. "Coleccionistas de objetos históricos, arqueológicos y de ciencias naturales en museos municipales de la provincia de Buenos Aires en la década de 1950", História, Ciencias, Saúde-Manguinhos, V. 12, 2005, pp. 205-229.

39 Sobre el "discurso criollista" ver: Adolfo Prieto. El discurso criollista en la formación de la Argentina moderna. Sudamericana. Buenos Aires, 1998.

40 Alejandro Cattaruzza. Descifrando pasados: debates y representaciones de la historia nacional. En A. Cattaruzza, (Dir.), Nueva Historia Argentina, 2001. 


\section{Contrastes en torno a la construcción del pasado indígena regional en espacios museográficos del sudeste bonaerense: un acercamiento desde las historias institucionales}

conservador y sectorial, que impide una aproximación plural y reflexiva sobre el pasado. El museo nunca promovió vínculos con entidades especializadas, incluso en una ciudad donde existen universidades y centros de estudios dedicados al pasado regional.

El problema central en este caso recae en que es el único museo histórico que existe en la ciudad y como tal recibe, además de turistas, visitas escolares durante la mayor parte del año. De esta forma, la salida educativa al museo se transforma en una reproducción de los discursos escolares decimonónicos, donde permanecen estereotipos y juicios de valor asociados a enfoques eurocéntricos propios del ideario político de fines del siglo XIX y principios del $\mathrm{XX}^{41}$.

Esto se vuelve aún más complejo si se tiene en cuenta que la institución museo, entendida como ámbito de educación no formal, cuenta con valiosos recursos que posibilitan la aproximación al pasado desde una óptica que se aleja de la historia escrita tradicional, permitiendo al visitante ser parte activa del proceso de comunicación cultural mediante montajes, recreaciones, etc. Como bien afirma Conforti, debido al debilitamiento actual de la superestructura que dio origen a la educación "formal" ha comenzado a emerger con mayor fuerza la educación no formal como una práctica legítima para el tratamiento de diversos temas de relevancia social que históricamente permanecieron relegados de la currícula escolar, como fueron las poblaciones indígenas ${ }^{42}$.

A modo de conclusión y luego del trabajo efectuado, se afirma que el museo municipal "José Hernández" se enmarca dentro de la denominada "Nueva Museología" en donde lo central es la capacidad de comunicación e interacción de la muestra. Para alcanzar esto se montó un recorrido que incluye reconstrucciones, secuencias didácticas, fotografías, soporte escrito, objetos y visitas guiadas interactivas que incluyen la participación del visitante. En contraposición, el museo "Fuerte Independencia" se enmarca dentro de la denominada "Museografía Tradicional" propia del siglo XIX, en donde la importancia de la muestra recae en los objetos. No existe un discurso articulador coherente en el recorrido ni relación entre las distintas salas que conforman la muestra, se considera que los objetos "hablan por sí mismos"43. El museo se transforma así en un lugar estático en donde no se contempla el rol del visitante. Asimismo, se homogeneiza a los pueblos indígenas bajo la denominación de "Indios Pampas" y se los representa de manera ahistórica, a partir de sus restos materiales -colecciones de puntas de proyectiles, vasijas, morteros, lanzas, etc.-

\footnotetext{
41 Irene Brichetti y José Vera. "Grandes corredores de la Pampa". Continuidades y... ¿rupturas? En las narrativas escolares sobre los indígenas que habitaron el territorio bonaerense, en Diana Mazzanti y Mónica Berón (directoras). Cazadores-Recolectores del Cono Sur. Revista de Arqueología. UNMDP, EUDEM, 2011.

42 María Eugenia Conforti. "Educación no formal y..., Op. Cit., p. 2

43 Marta Dujovne. Entre musas y musarañas..., Op. Cit., p. 5.
} 


\section{Felicitas Sánchez Azcárate}

En este sentido, el museo situado en la ciudad de Tandil no intentó nunca renovar su discurso museológico ni museográfico, por lo que continúa reproduciendo un relato hegemónico, no solo sobre las sociedades indígenas, sino también sobre la historia de la ciudad, y no en menor medida, sobre la historia del Estado nacional argentino.

\section{Bibliografía}

Adolfo Prieto. El discurso criollista en la formación de la Argentina moderna. Sudamericana. Buenos Aires, 1998.

Alejandro Cattaruzza. Descifrando pasados: debates y representaciones de la historia nacional. En A. Cattaruzza, (Dir.), Nueva Historia Argentina, 2001.

Cesar Román. Cuando Mar del Plata era Campo. Ediciones Suarez, 2004.

Cuadernillo Informativo de circulación interna. Asociación Museo Tradicionalista Argentino José Hernández, años (1963-1975), en Archivo del Museo Municipal José Hernández (AMJH). Mar del Plata, Laguna de los Padres, pp. 1-12.

Cuadernillo Informativo de Inauguración de la Sede Social Museo y Biblioteca Fuerte Independencia año 1963, en Biblioteca/Archivo del Museo Histórico Fuerte Independencia (AMHFI). Tandil, pp. 1-2.

Estatuto de la Institución Tradicionalista Fuerte Independencia en Biblioteca/Archivo del Museo Histórico Fuerte Independencia (AMHFI). Tandil, año 1964, p 1.

Felicitas Sánchez Azcárate. “Cuando el mito supera la realidad: La figura de José Hernández y su pasaje por la Laguna de los Padres", presentado en II jornadas Martinfierristas, Ayacucho, Buenos Aires, 2013.

Informe de Asesoramiento Museológico para el Museo Municipal José Hernández (1996-1997), en Laboratorio de Arqueología Regional Bonaerense. Mar del Plata, pp. 4-19.

Irene Brichetti. La construcción del pasado regional en museos del sudeste de la provincia de Buenos Aires. Tesis de Licenciatura en Historia, Facultad de Humanidades de la Universidad Nacional de Mar del Plata, 2008.

Irene Brichetti. "Sabios, exploradores y artesanos. Amalgamas del pasado en la Mar del Plata de primera mitad del siglo XX (1924-1954)". RMA Museología, 2014.

Irene Brichetti y José Vera. "Grandes corredores de la Pampa". Continuidades y... ¿rupturas? En las narrativas escolares sobre los indígenas que habitaron el territorio bonaerense, en Diana Mazzanti y Mónica Berón (directoras). CazadoresRecolectores del Cono Sur. Revista de Arqueología. UNMDP, EUDEM, 2011.

Isabel Lamonier. Museo y Sociedad, Centro Editor de América Latina, Buenos Aires.1993.

José Antonio Pérez Gollán. "La situación del patrimonio cultural en la Argentina, Mesa redonda: en el país de nomeacuerdo, Ciencia Hoy 3 (16): 32.1991. 


\section{Contrastes en torno a la construcción del pasado indígena regional en espacios museográficos del sudeste bonaerense: un acercamiento desde las historias institucionales}

María Alejandra Pupio. “Coleccionistas de objetos históricos, arqueológicos y de ciencias naturales en museos municipales de la provincia de Buenos Aires en la década de 1950", História, Ciencias, Saúde-Manguinhos, V. 12, 2005, pp. 205-229. María Elida Blasco. Un museo para la colonia. El Museo Histórico y Colonial de Luján (1918-1930), Rosario: Prohistoria, 2011, pp. 21-139.

María Eugenia Conforti. "Educación no formal y patrimonio arqueológico. Su articulación y conceptualización". Intersecciones en Antropología. Facultad de Ciencias Sociales - UNCPBA - 11: 103-114. 2010. ISSN 1666-2105, 2010, p 6. María Luz Endere y José Luis Prato. Patrimonio, ciencia y comunidad. Su abordaje en los partidos de Azul, Olavarria y Tandil. INCUAPA, UNCPBA, 2009, pp. 19-37.

Mariano Nagy. "Los museos de la última frontera bonaerense y sus narrativas acerca de los pueblos indígenas". Revista del Museo de Antropología. Facultad de Filosofía y Letras 6: 79-90. UBA. ISSN: 1852-060X, 2013.

Marta Dujovne. Entre musas y musarañas. Una visita al museo. Fondo de cultura económico, Montevideo.1995

Recibido: $10 / 09 / 2016$

Evaluado: $27 / 10 / 2016$

Versión Final: 24/11/2016 